\title{
Editorial
}

\section{Physics and Music}

Albert Einstein was famously devoted to his violin; Max Planck, Werner Heisenberg, and Edward Teller were serious pianists. Against many other examples of musical physicists, Erwin Schrödinger was considered exceptional for being unmusical. Is there some intrinsic connection between physics and music?

The devotion of these physicists to music seems more than mere diversion, or escape from the demands of scientific research, or being a Kulturträger, a "bearer of culture." Their knowledge, ability, and respect for music and musicians is marked by sincerity, depth, and genuine passion. On one occasion, after playing Beethoven's last piano sonata (op. 111) at a party, Heisenberg stood up and told the spellbound audience, "If I had never lived, someone else would probably have formulated the uncertainty principle. If Beethoven had never lived, no one would have written op. 111."1

As one of us argues in a recent book, music had an important role in shaping the development of modern science, especially of physics. ${ }^{2}$ Music figured strongly in Kepler's search for cosmic harmonies, in Newton's theory of colors, in Thomas Young's work bridging sound and light, in nascent developments of electricity and magnetism, and in analogies between overtones and spectral lines. Max Planck experimented with an innovative harmonium and with choruses just before he began working on blackbody radiation. More speculatively, historian Stillman Drake suggested that the composer and lutenist Vincenzo Galilei's musical experiments deeply influenced his son Galileo's application of experimentation to natural science.

What about today? Do the latest generations of physicists share these passions, or did they fade as the postwar European emigrés themselves recede into the past? We suspect that here, as in other respects, physicists reflect the larger culture from which they emerge; as classical music has seemed to vanish from the center of culture, its audience ever grayer, it likewise no longer claims the deep emotional charge it had for the European emigrés. Still, music has not vanished from physics, as evidenced by the all-pervasive musical analogies in popular discussions of string theory, as well as intriguing efforts to "sonify" experimental data. ${ }^{3}$

Rather guardedly, Einstein thought that "music does not influence research work, but both are nourished by the same sort of longing, and they complement each other in the satisfaction they offer." 4 Yet his sister thought that his musical reveries were no mere distraction, because "they put him in a peaceful state of 
mind, which facilitated his reflection. For later on, when great problems preoccupied him, he often suddenly stood up and declared: 'There, now I've got it.'" Through music, "a solution had suddenly appeared to him." ${ }^{5}$ Our need for solace when seeking solutions remains just as deep as ever, and music is surely just as able to provide it.

In this issue, Kevin Lambert shows us that the relation between music and scientific philosophy during the early modern period was complex. Lambert describes how the composer and music theorist Jean-Philippe Rameau used the basic overtones of a vibrating body to dramatize the mythical sculptor Pygmalion bringing his beautiful statue to life. In so doing, Rameau also appealed to contemporary speculations about the nature of matter. Music, Lambert shows, was not only an important ingredient of but also a positive, if subtle, force in intellectual discourse at a time when the authority of Cartesian mechanical philosophy was declining and the empiricist approach of John Locke and others was on the rise.

We suspect that the relation between music and physics is also complex today, going far beyond solace, even beyond such desiderata as symmetry, variation, development, beauty, and order; we look forward to more articles exploring this important relation.

Robert P. Crease Peter Pesic

\section{References}

${ }^{1}$ Owen Gingerich, ed., The Nature of Scientific Discovery (Washington, DC: Smithsonian Institution, 1975), 496.

${ }^{2}$ Peter Pesic, Music and the Making of Modern Science (Cambridge, MA: MIT Press, 2014), which discusses the examples mentioned here.

${ }^{3}$ For a critical treatment, see Peter Pesic and Axel Volmar, "Pythagorean Longings, the Rhetoric of String Theory, and the Sonification of High-Energy Physics," Journal of Sonic Studies 8 (2014).

${ }^{4}$ From a 1928 letter to Paul Plaut, cited in Albert Einstein, Albert Einstein, the Human Side: New Glimpses from His Archives, ed. Helen Dukas and Banesh Hoffmann (Princeton, NJ: Princeton University Press, 1979), 78.

${ }^{5}$ Albert Einstein, Collected Papers, ed. John Stachel (Princeton, NJ: Princeton University Press, 1987), 1:1xiii [translation: xxi]. 